\title{
O trabal ho em saúde bucal do Agente Comunitário de Saúde em Unidades deSaúde da Família
}

\author{
The work in oral health of the community health agent \\ in family health units
}

GinaAyumi Kobayashi Koyashiki ${ }^{1}$

Rosani Aparecida Alves-Souza ${ }^{1}$

M aria Lucia Garanhani ${ }^{1}$

\footnotetext{
${ }^{1}$ Universidade Estadual de Londrina. Av. Robert Koch 60 , Vila O perária. 86039-440, Londrina PR. ginakoyashiki@yahoo.com.br
}

Abstract Thepresent study aimed at understanding the work of the Community $\mathrm{H}$ ealth Agent $(\mathrm{CHA})$ in the field of Oral $\mathrm{H}$ ealth in Brazilian Family Health Units (FHU) in 2005. This study represents a qualitative approach to the meanings and feelings that underlie the know-how in Oral $\mathrm{H}$ ealth of the $\mathrm{CHA}$, showing his experience in this process. The sample consisted of nine $\mathrm{CH}$ As from two Family $\mathrm{H}$ ealth U nits. Data were collected in interviews with four guiding questions. The statements were analyzed using discourse analysis. It was observed that the $\mathrm{CH}$ As recognize the importance and demand for more qualification and re qualification opportunities enabling them to overcome the feeling of limitation expressed in their discourse.

Key words Community Health Agent, Oral health, Qualitative research
Resumo 0 presenteestudo buscou compreender 0 trabalho em saúde bucal do Agente Comunitário deSaúde(ACS) em Unidades deSaúdeda Família (USF), no ano de 2005. Para tanto, utilizou-se de uma abordagem qualitativa com o intuito decompreender os significados esentidos que permeiam 0 saber e o fazer em saúde bucal do ACS, mostrando sua vivência neste processo. A amostra compreendeu noveACS, deduas USF da rede deprestação de serviços. 0 acesso às informaçoes realizou-se por meio de entrevista conten do quatro questões norteadoras. Para a análise dos relatos, recorreu-se à técnica da análise do discurso, eassim foi possível perceber que os ACS reconhecem a importância e demandam mais oportunidades de qualificação e requalificação, como forma de superar sentimentos de limitação expressos em seus discursos.

Palavras-chave Agente Comunitário de Saúde, Saúde bucal, Pesquisa qualitativa 
Introdução

No Brasil, a meta com priorização da atenção primária, "Saúde para todos no ano 2000", registrada na Declaração de Alma-Ata ${ }^{1}$, inspirou a criação do Sistema Ú nico de Saúde (SUS), cujos princípios privilegiam o entendimento da saúde enquanto um direito inerenteà cidadania eo acesso universal aos bens e serviços afins.

Assim, o SUS comparece no cenário sanitário brasileiro com a missão de romper o caráter excludente do modelo assistencial anterior, de forma a assistir os milhões de excluídos do processo debusca por melhores condições de vida e saúde.

Dentro da perspectiva de formulação e desenvolvimento de políticas públicas de saúde, com ênfase na valorização dos cuidados primários, considera-se que a Declaração de Alma-Ata deu novo direcionamento às políticas de saúde por permitir o desenvolvimento da atenção primária como principal estratégia de promoção eassistência à saúde e estimular a participação comunitária.

Concorde às premissas da atenção primária à saúde, em 1991, o M inistério da Saúde/Fundação Nacional da Saúde criou o Programa de Agentes Comunitários de Saúde (PACS) com objetivo de estimular na população a questão do autocuidado, mediante o repasse de informações para a saúde por meio dos Agentes Comunitários de Saúde (ACS).

Desse modo, compreende-se o ACS como instrumento de articulação entre os serviços de saúde e a comunidade, uma vez que desenvolve ações básicas de saúde e atividades de caráter educativo, contribuindo, assim, para a construção e consolidação de sistemas locais de saúde².

Como estratégia do modelo de atenção básica, direcionada à reestruturação do modelo assistencial e fundamentada na lógica da promoção de saúde, surge no ano de 1994 o Programa Saúde da Família (PSF) , o qual prioriza ações de promoção, proteção, controle e manuten ção da saúde dos indivíduos e da família, de forma integral e contínua?

Através da Pesquisa Nacional por Amostragem Domiciliar (PNAD), realizada em 1998, o Instituto Brasileiro de Geografia e Estatística (IBGE) constatou queum número expressivo de 29,6 milhões de brasilei ros nunca foram ao dentista. Frente a esse alarmante resultado, o M inistério da Saúde, em 2000, anuncia a inclusão das Equipes de Saúde Bucal (ESB) no PSF, com objetivos definidos para a diminuição dos índices epidemiológicos e a ampliação do acesso da população brasileira às ações de saúde bucal ${ }^{4}$.
Pode-se entender esse quadro de exclusão social como resultado de uma prática odontológica excludente, que persistiu por longo período, a qual se caracterizava por priorizar populações definidas como escolares de redes públicas, que relegava a população adulta aos atendimentos de urgência, que na maioria das vezes levavam à mutilação, muito mais do que qualquer possibilidade de resolução do problema ${ }^{5-8}$.

Ao que se refere às reflexões acerca da inserção da saúde bucal no PSF, considera-se o PSF como sendo mais do que um espaço social, mas onde as mudanças e a reorganização do processo de trabalho em saúde podem acontecer. Um espaço onde as práticas de saúde recebem uma nova dinâmica, de modo a romper a organização disciplinar tradicional, fragmentada de maneira a formar vínculos, propondo alianças com outros setores, permitindo dessa forma maior diversidade das ações, além de potencializar as formas de produzir saúde, fortalecendo a relação sistema-usuário.

Compreendendo a saúde bucal como um dos componentes da saúde em sua expressão mais ampla, Souza et al. ${ }^{9}$ elaboraram uma proposta baseada na busca de mecanismos que visam à melhoria do quadro epidemiológico, por meio da ampliação das ações em saúdebucal. Respaldados pel as características da atuação do ACS e pela rápida expansão do programa ocorrida no país e buscando construir novos processos de trabalho voltados para a família, os autores apontaram os ACS como mecanismos capazes de prover facilidades ao processo de desenvolvimento das ações em atenção primária e também em saúde bucal.

$\mathrm{Na}$ visão de Souza e Sampaio ${ }^{10}$, são muitos os desafios trazidos pelo PSF, uma vez que se encontram coesos, sob forte relação de dependência, principalmente aqueles relacionados ao planejamento e gestão dos serviços, recursos humanos e outros mais. N esse sentido, para que os objetivos do PSF sejam consolidados, os autores chamam a atenção para a necessidade de priorizar as ações de atenção básica, de modo a resultar na ampliação e na garantia do acesso a serviços mais resolutivos, oportunos e humanizados para toda população brasileira.

Sob foco da dinâmica dos serviços ecom base nos princípios e pressupostos do SUS, M otta et al. ${ }^{11}$ defenderam a necessidade de qualificação e requalificação da força de trabalho, de modo a resultar em sujeitos competentes, comprometidos com o processo de construção social da saúde, por meio de atitudes reflexivas ecríticas acerca do seu papel enquanto sujeito-usuário. 
Visando salientar a importância do ACS como agente de mudança dentro da dimensão sujeito-usuário, vale recorrer à citação de Tollendal ${ }^{12}$, que diz "antes desai rmos buscando a felicidade, devemos nos perguntar o que fizemos para sermos dignos dela?!!" E ainda: Cada agente de saúdedeveser um instrumento transformador. Esta éa mudança inadiável, porquenão se detém o processo temporal. Para haver mudança, no sentido de mutação, de transformação, esta tem que vir apoiada ou referenciada a um quadro devalores. É necessário que o processo de transformação se instale pela educação que vem da informação, esta gera inter esse, e este necessidade, que leva a ação motivada. Ação é dinâmica e ação total é mutação. D esta cadeia defatos surge a liberdade quenão vem como resultado de revolta. Vem naturalmente, por haver intenção necessária ${ }^{12}$.

Muito embora se tenha noção do volume de atribuições quelheéconferido, percebe-seo ACS como sendo instrumento devalor inestimável ao processo de construção social da saúde, uma vez quesua atuação oferece possibilidades deimportantes avanços rumo à integralidade da atenção.

O conteúdo acima exposto abre espaço para justificar a elaboração do presente estudo, diante das reflexões surgidas acerca do processo de trabalho do ACS em saúde bucal, principalmenteao quese refereà efetivação das ações promocionais.

\section{Metodologia}

A principal inquietação quemotivou o desenvolvimento deste estudo foi saber "Como é o trabaIho em saúde bucal do Agente Comunitário de Saúde".

Para aproximação do fenômeno, foi utilizada uma abordagem qualitativa, visto que a mesma proporciona a compreensão das experiências vivenciadas, apreendidas a partir do olhar do pesquisador, traduzindo-se na captação de fragmentos do mundo-vida ou parte de uma realidade do homem, construída evivenciada por el $\mathrm{e}^{13}$.

Como etapa inicial, este estudo foi aprovado pelo Comitê de Ética em Pesquisa Protocolo $n^{\circ}$ 177/05, seguindo os requisitos preconizados pela Resolução 196/96 do Conselho Nacional de Saúde (CNS).

O bteve-se a autorização da Gerência de Capacitação de Pessoas, da Autarquia M unicipal de Saúde de Londrina, Paraná.

Os sujeitos envolvidos no estudo compreenderam nove ACS, de duas USF da rede de prestação de serviços, sendo cinco deles pertencentes a uma USF localizada na região central do município e os quatro restantes, de uma USF da região norte.

A participação dos sujeitos deu-se de forma voluntária, mediantea solicitação depermissão para a gravação ea explicitação sobrea finalidade e importância da colaboração, seguida da assinatura do termo de consentimento livre eesclarecido.

Esclarece-se que este número de entrevistados foi suficiente para a composição do universo amostral, uma vez que, por meio do critério de saturação, os discursos começaram a se repetir, apresentando convergências suficientes para a análise do fenômeno estudado.

A forma de acesso utilizada para aproximarse da situação vivida dos sujeitos envolvidos foi a entrevista com as seguintes questões abertas:

1) 0 que você entende por saúde bucal?

2) De onde você obtém as informações sobre saúde bucal?

3) 0 que você acha importante saber sobre saúde bucal?

4) Q ue sugestão você daria para o aprimoramento de suas atividades?

Como artifício metodológico para a condução da entrevista, Garanhani ${ }^{14}$ destaca a necessidade de criar um ambiente tranqüilo e de confiança, de modo a permitir um espaço desprovido de interferências limitantes ao discurso dos entrevistados, ou seja, um discurso livre de constrangimentos.

Somente foram utilizadas outras perguntas durante a entrevista quando houve necessidade, para facilitar a continuidade do depoimento. Estas perguntas foram as seguintes: "Gostaria de falar mais alguma coisa sobre isto? Você quer contar mais alguma coisa sobre a sua experiência? Gostaria de dizer mais alguma coisa?". Além desse artifício metodológico, foi utilizado o recurso de repetir a última frase dita pelo entrevistado para que ele continuasse seu raciocínio.

Após a realização das entrevistas, as mesmas foram transcritas.

Para a análise das entrevistas, foi utilizada a seqüência preconizada por $M$ artins e Bicudo ${ }^{15}$, que abrange dois momentos: 0 da análise ideográfica ou individual e o da análise nomotética ou geral.

O primeiro momento, representado pela análise ideográfica ou individual, se refere à articulação dos significados presentes em cada entrevista, nas suas inter-relações e na sua unidade estrutural. São três as etapas da análise ideográfica, a saber: $1 \underline{\underline{a}}$ etapa: leitura das entrevistas; $2^{\underline{a}}$ etapa: recorte das unidades de significado; $3^{\text {a }}$ etapa: interpretação das unidades de significado. 
A pós a transcrição dos discursos, foram identificados quarenta e três agrupamentos de unidades de significado que, cruzados entre si, caminharam para nove convergências temáticas (Quadro 1).

A análise nomotética ou geral, a qual corresponde ao segundo momento, envolveum movimento de passagem do individual para o geral, resultante da compreensão das convergências e das divergências presentes na manifestação do fenômeno interpretado na análiseideográfica. São três as etapas da análise nomotética, a saber: 1 a etapa: leitura e re-leitura das temáticas; $2^{2}$ e etapa: entendimento do fenômeno; 3ạ etapa: desvelamento do fenômeno.
As nove convergências temáticas confluíram para quatro categorias abertas que configuram a estrutura geral do fenômeno investigado, demonstradas na Figura 1.

Importante acrescentar que, diante da análise de percepções, o pesquisador deveter em mente a noção de que a realidade do fenômeno investigado não está pronta, apresentando-se apenas como um fato. Entretanto, ao pesquisador édada a orientação para a sua construção e descoberta por meio do discurso do sujeito que vivencia a experiência, uma vez queum fenômeno nunca se mostra por completo.

Quadro 1. Demonstrativo das nove Convergências Temáticas construídas a partir das Unidades de Significado.

\begin{tabular}{|c|c|c|c|c|c|c|c|c|c|c|}
\hline \multirow{2}{*}{\multicolumn{2}{|c|}{$\begin{array}{l}\text { Proposições dos sujeitos } \\
\text { Agentes Comunitários de Saúde }\end{array}$}} & \multicolumn{9}{|c|}{ Convergências temáticas } \\
\hline & & \multirow{2}{*}{$\begin{array}{l}1 \\
x\end{array}$} & \multirow{2}{*}{2} & \multirow[t]{2}{*}{3} & \multirow[t]{2}{*}{4} & \multirow{2}{*}{5} & \multirow[t]{2}{*}{6} & \multirow[t]{2}{*}{7} & \multirow{2}{*}{$\begin{array}{l}8 \\
x\end{array}$} & \multirow{2}{*}{$\begin{array}{l}9 \\
x\end{array}$} \\
\hline 1.1 & $\begin{array}{l}\text { Saúde bucal revela-se como algo } \\
\text { muito importante e que concretiza a } \\
\text { realidade da identidade da pessoa. }\end{array}$ & & & & & & & & & \\
\hline 1.2 & $\begin{array}{l}\text { Revela que nem todas as pessoas têm } \\
\text { acesso aos serviços de } 0 \text { dontologia. }\end{array}$ & $x$ & $x$ & $x$ & & & & & & \\
\hline 1.3 & $\begin{array}{l}\text { Saúde bucal mostra-se como algo em } \\
\text { crescimento para tornar-se acessível } \\
\text { às pessoas. }\end{array}$ & $x$ & & $x$ & & & & & $x$ & \\
\hline 1.4 & $\begin{array}{l}\text { Relembra como adquiriu os seus } \\
\text { conhecimentos em saúde bucal }\end{array}$ & $\mathrm{X}$ & $x$ & $X$ & $X$ & & $X$ & $x$ & $x$ & $x$ \\
\hline 1.5 & Como caracteriza a saúde bucal. & $\mathrm{X}$ & $\mathrm{X}$ & $x$ & $x$ & $X$ & $X$ & $x$ & & \\
\hline 1.6 & $\begin{array}{l}\text { Fala sobre a importância do } \\
\text { autocuidado e do auto-exame na } \\
\text { saúde bucal. }\end{array}$ & $\mathrm{X}$ & & & & $x$ & & $x$ & & \\
\hline 1.7 & $\begin{array}{l}\text { Fala sobre um sentimento de } \\
\text { limitação que permeia sobre o } \\
\text { cotidiano quando executa suas ações } \\
\text { de saúde bucal na população. }\end{array}$ & & & $x$ & $x$ & & & & & \\
\hline 1.8 & $\begin{array}{l}\text { Saúde bucal significa educar e } \\
\text { promover mudanças de hábitos. }\end{array}$ & & $x$ & $x$ & $X$ & & & & & $x$ \\
\hline 1.9 & $\begin{array}{l}\text { Enfatiza a importância dos } \\
\text { conhecimentos adquiridos e sugere } \\
\text { que deveria ter mais conhecimentos. }\end{array}$ & & $x$ & $x$ & & $\mathrm{X}$ & $x$ & $x$ & $x$ & $x$ \\
\hline
\end{tabular}


1. Saúde bucal revela-se como algo muito importante e que concretiza a realidade da identidade da pessoa.

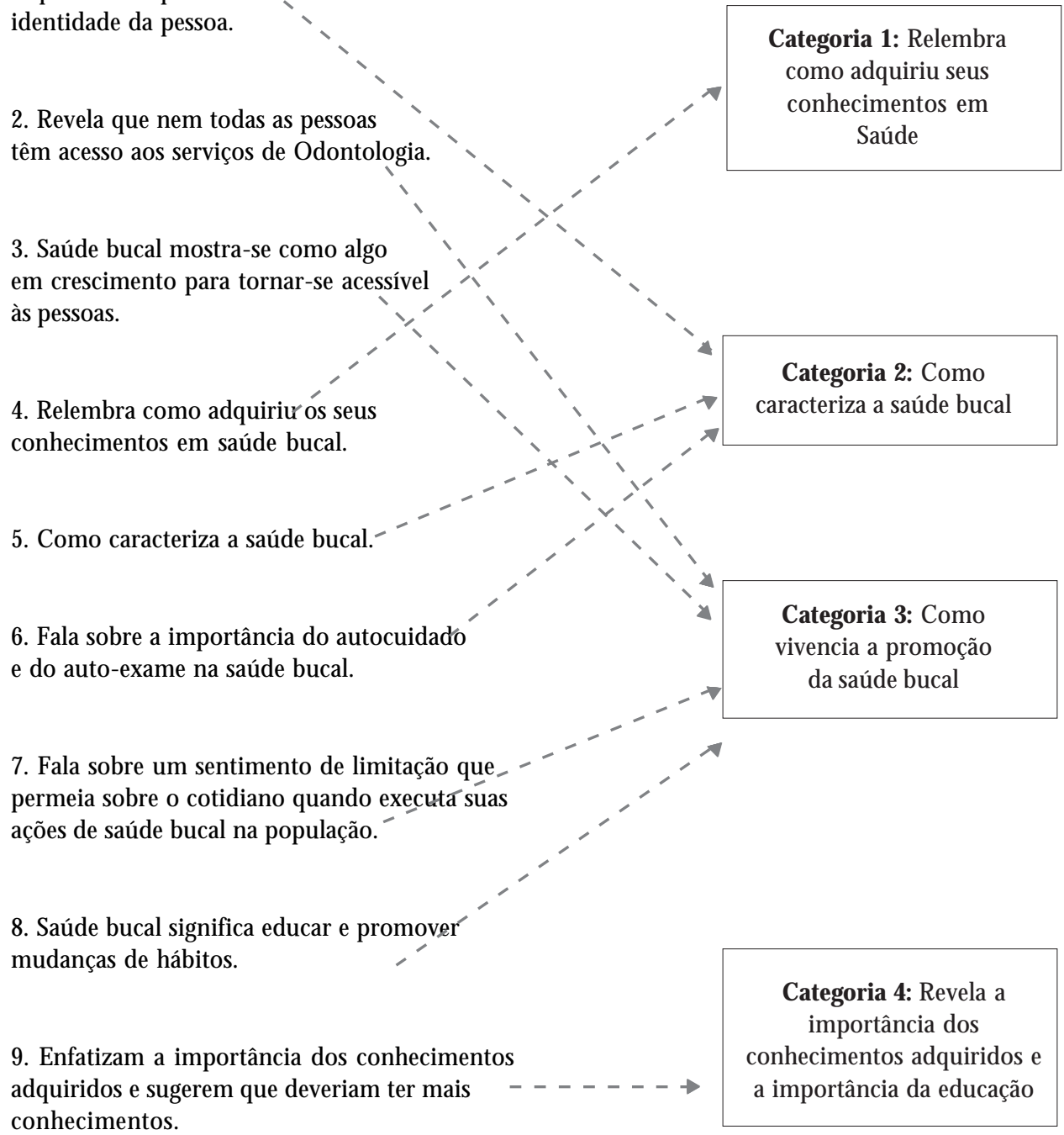

Figura 1. Demonstrativo das quatro Categorias Abertas construídas a partir das nove Convergências Temáticas.

\section{Descrição das categorias}

O fenômeno, dada a sua subjetividade, éincompreendido na sua totalidade; contudo, algumas compreensões são desveladas durante a trajetória da busca por sua interpretação. Várias perspectivas são identificadas ao se colocar o fenômeno em suspensão, indican do a necessidade do pesquisador em posicionar-se numa condição de neutralidade edesprover-se dereferenciaisteóricos prévios, sem, contudo, afastar-se dos referenciais vividos e expressos.
É importante destacar quea manifestação do fenômeno setorna mais clarificada à medida que maior número de análises vai sendo requerido a sua compreensão.

A primeira categoria se configura com base no questionamento dos meios sobre os quais os ACS obtiveram o conhecimento em saúde bucal, ou seja, os entrevistados relembram como adquiriram os seus conhecimentos sobre saúde bucal:

"os conhecimentos que adquiri quando implantou o PSF, com o dentista daqui e que não faz muito tempo". (1) 
"aqui mesmo no posto de saúde, com as auxiliares de odontologia, com o dentista". (6)

" eu obtive mais lendo, através de pesquisa, e depois que eu entrei na área da saúde, quando eu precisei do serviço do dentista. 0 dentista me orientou também". (7)

"Eu obtive com a dentista mesma, quando a gente tem alguma dúvida, a gente pergunta para ela e ela responde e a gente passa para frente". (9)

A questão da socialização do conhecimento é evidenciada nos discursos acima apresentados, nos quais se tem ganho destaque uma atitude de busca da informação para a saúde bucal.

Outra questão percebida na análise diz respeito à ausência de processos formadores voltados à qual ificação profissional em saúdebucal, de modo a tornar a prática do cuidado à saúde mais integral, de características mais integral izadoras.

Buscando referencial teórico para ilustrar a questão do conhecimento na formação dos ACS, recorreu-se ao estudo de Robayo citado em Wright ${ }^{16}$, publicado em 1987, no qual se encontra registrada a sugestão para a oferta de treinamento elementar, em curto prazo, considerada a partir da necessidade de se preparar o recurso humano para um desempenho profissional coerente às demandas expressas pela comunidade, acrescida da orientação para uma ampliação gradativa.

Nessa mesma linha de raciocínio, Nunes et al. ${ }^{17}$ consideraram que o treinamento deve prover conhecimentos diversos em torno da questão do processo saúde-doença, além de facilitar a formação de outras competências e habilidades, fora da dimensão biomédica, para uma meIhor atuação do profissional junto às famílias e para o reconhecimento de suas necessidade.

Percebe-se, no entanto, que a formação recebida pelos ACS tem sido o espel hamento da formação que outros membros da equipe de Saúde da Família receberam, ou seja, podem estar reproduzindo princípios assistenciais voltados às práticas curativistas.

A segunda categoria se representa pela caracterização da saúde bucal, ou seja, como o ACS caracteriza a saúde bucal. A seguir, têm-se os discursos:

"é tudo, estar tratando dos dentes, não deixar a cárie aparecer para você ir ao dentista. É começar a tratar antes, desde o bebezinho". (2)

"uma boa escovação. Saúde bucal é higiene, até quem tem dentadura". (4)

étrazer seu filho ao dentista, fazer higiene, escovar pelo menos três vezes ao dia, usar o fio dental. Estar fazendo uma revisão, adulto, criança. I doso é muito importantetambém para estar veri- ficando mesmo que usa prótese dentária, para ele estar fazendo uma avaliação. (6)

"saúde bucal é prevenção. Importante, é a gente saber para prevenir, como eu disse, para prevenir futuras doenças, principalmente o câncer de boca". (7)

Em concordância às percepções, torna-se possível compreender que se atribui à "saúde bucal" um sentido de prevenção da cárie dentáriae de doenças da boca. E entende-se o "cuidado com a saúde bucal" como sendo práticas de higiene dental e escovação, tanto na pequena idade quanto na idade adulta, além da noção de que, diante da ausência dos dentes, o cuidado deve implicar uso de prótese dentária.

Pode-se perceber, ainda, que dos discursos emerge a noção de saúde bucal sob uma perspectiva ampliada do processo saúde-doença, surgindo também o entendimento da boca para além do anátomo-fisiológico, ou seja, como extensão corporal com significados e sentidos próprios ${ }^{18}$.

"a saúde bucal tem que ser muito importante na saúde das pessoas". (1)

"saúde depende de um todo, é um todo, é o corpo todo. E que a doença da boca vai prejudicar o estômago, vai prejudicar todo o resto do corpo". (2)

"saúde bucal faz partedo corpo, e como parte do corpo também tem que ser cuidada". (8)

Entende-se que, para haver o fortalecimento da consciência para o cuidado em saúde bucal no sentido promocional, torna-se imperiosa a necessidade de compreender a boca como a extensão deum todo, num todo, firmando-secomo recurso essencial para uma vida cotidiana com qualidade.

A essência desses desafios teórico-conceituais fica evidentena citação de Souza ${ }^{18}$ : A integralidade na Atenção à Saúde Bucal só será alcançada se, em nossas práticas e em nossa formação, buscarmos devolver à boca suas dimensões cultural e psíquica para que passemos a olhá-la não apenas como máquina de mastigar, mas também como máquina de desejo, como lugar onde também se afirmam sujeitos desejantes e produtores do mundo ${ }^{18}$.

Para os entrevistados, o autocuidado e autoexame na prevenção de doenças da boca são atitudes importantes na dimensão do cuidado em saúde bucal, assim como a figura do profissional tida como articulador entre dois campos de intervenção: de informação para saúdee deacesso ao controle, manutenção e prevenção de doenças. N esse sentido, 0 entendimento por parte do profissional quanto ao seu desempenho como educador é de fundamental importância, deven- 
do o mesmo estar sensível às necessidades subje tivas e culturais do usuário, bem como deveadotar uma comunicação dialógica direcionada a uma assistência diferenciada e de estímulos pela busca da autonomia em saúde.

acho importante a população, assim como eu, eu também faço parte da população, estar sabendo que eu preciso ter uma escovação diária. Eu preciso estar cuidando mesmo, porque se eu vir alguma coisa diferente na minha boca estar procurando um dentista. (1)

"saúde bucal éa genteestar fazendo um autoexame, para prevenir doenças na boca. A gentese olhar no espelho e ver se tem alguma feridinha, alguma mancha". (7)

Importanteapresentar o desenvolvimento de habilidade, como um dos campos de ações identificados na Carta de Ottawa ${ }^{19}$, que se fundamenta na implantação de políticas públicas sob a lógica da promoção de saúde e no desenvolvimento da capacidade de análise crítica da realidade. 0 documento deixa claro a importância da socialização de informações para o desenvolvimento de habilidades favoráveis à saúde. Ou seja, orienta para o estabelecimento de práticas educativas nos mais diferentes espaços coletivos, de maneira a preparar o indivíduo para a superação de dificuldades da existência e o enfrentamento das enfermidades.

Em sintonia à assertiva acima apresentada, tem-se logo abaixo o comentário de Buss $^{20} \mathrm{em}$ reforço à prática do empowerment como conseqüência de intervenções de promoção de saúde efetivas: 0 s indivíduos e as comunidades devem ter oportunidade de conhecer e controlar os fatores determinantes da sua saúde. Ambientesfavoráveis, acesso à informação, bem como oportunidades para fazer escolhas mais saudáveis, estão entre os principais elementos capacitantes.

A implementação do empowerment tem sido objeto deinúmeras discussões no campo da promoção da saúde e das ciências sociais em geral. Porém, nos últimos tempos, esse conceito fundamental da promoção de saúdetem sido parcialmente encoberto por outros conceitos, como decapacitação comunitária, coesão social e capital social ${ }^{21-23}$, os quais integram as discussões acerca da saúde e da qualidade de vida; contudo, deixam de enfatizar a questão das relações de poder (empoderamento) como "determinante fundamental da saúde"22.

Para Sem ${ }^{24}$, o empowerment está relacionado com as reais facilidades de acesso à participação e desenvolvimento individual. Para Laverack e Labonte ${ }^{25}$, é tido como estratégia para aquisição de controle sobre as decisões em saúde ou como um mecanismo de mudanças direcionadas a uma igualdade de poder, sobretudo àquelas que concentram recursos, legitimidade, autoridade ou influência.

$\mathrm{Na}$ opinião de Vasconcelos ${ }^{26}, 0$ empowerment valoriza a ação local de grupos sociais voltada à formação de aliança com a finalidade de ampliar o debate acerca da opressão, mediante sua contextualização, ao mesmo tempo em quebusca sua compreensão como fenômeno histórico, estrutural epolítico. Ao se privilegiar a co-participação de vários sujeitos com suas diferentes realidades, em processos de busca por melhorias de vida e saúde, tem-se o fortalecimento do tecido social de forma a abrir possibilidades de escol has aos diferentes indivíduos, deixando-os livres para optar por tudo aquilo que proporcione saúde.

Em continuação à caracterização da saúde bucal, podese perceber em um dos discursos que a mesma é imprescindível para a concretização da identidade, pelo fato de o rosto atrair o primeiro ol har das pessoas e por ser o local onde se estampa a realidade da identidade de cada um.

"o sorriso é a identidade da pessoa. Se você não tem uma identidade o que vocêseria?" (1)

Tomando o rosto como centro da noção, Wolf ${ }^{27}$ relatou a importância da boa aparência como um instrumento facilitador para a aceitação do indivíduo pelo grupo social, destacando o sorriso e dentes saudáveis como símbolos importantes da auto-apresentação.

Atualmente, a sociedade supervaloriza a aparência em detrimento de outros valores, interpretando a falta de dentes como sendo uma condição estética esocialmente desfavorável com capacidade de excluir as pessoas do convívio social ${ }^{28}$.

Ainda sobre a construção da identidade do indivíduo, a saúde bucal ea boa conservação dos dentes, $M$ artins $s^{29,30}$ identificou quea falta dedentes desvaloriza ou incapacita o trabalhador enquanto força de trabalho, do mesmo modo que o trabalho resgata a saúde bucal enquanto valor.

A terceira categoria se mostra com as falas dos ACS vivenciado a Promoção de Saúde Bucal e percebe-se que educar e promover mudanças de hábitos não é tarefa das mais fáceis.

Você vai até a pessoa, consegue orientar, você consegue ver que as crianças estão melhores acompanhadas. M uitas vezes você tem que insistir muito, tem quetrabal har muito, mas às vezes vocêconsegue. Na maioria das vezes você consegue. E a população ainda está naquela idéia de medicamento, que o medicamento é que vai resolver, mas na realidade não éisso. É um trabal ho de prevenção, a 
população não aprendeu ainda a prevenir. E mais importante prevenir do que estar só medicando, medicando. Eles deixam tudo para a hora que não tem mais condições. Tem que ser passado para a população, para quea população tenha consciência que não ésó vir ao dentista quando está com dor ou está com cárie. É começar antes o tratamento. Orientação e que a doença da boca vai prejudicar 0 estômago, vai prejudicar todo o resto do corpo. (2)

$N$ ão é difícil trabalhar com prevenção, só que muitas vezes a gente passa uma orientação, só que por hábitos do paciente mesmo, ele não faz. Então a gente, bateem cima, fala, que tem queter higiene bucal, fazer limpeza, passar fio dental. M as no fundo, no fundo, na hora que você vira as costas, ele pára, el e faz 1, 2, 3 dias, só que ele vê que não dá, queninguém está mais perturbando, ninguém está falando, ele pára, daí começa tudo denovo. Eu sou de uma área mais idosa, não tem tanta criança. M eus pacientes são de 45 para cima. Então você sabe que é prótese, não faz a higiene que tem que ser feita. Eles dormem com a prótese, eles não fazem, não tiram a prótese para dormir, não faz uma higiene, não põem no copo, ou deixa lá com água. Daí você fala: "D ona M aria, a senhora tira a prótese para dormir?". "Tira a dentadura para dormir, Dona M aria?", "Ah, fia, eu tô acostumada já". É isso queeles falam, às vezes elesfalam assim: "Ah, eu não fui acostumada com isso", "ah, eu só lavo a boca". Então você sabe que não é uma higiene. Já não é um costume. Até mesmo quando tinha dentes talvez não era costume. Já vem de descendência talvez, ou então de pai para filho. É difícil fazer prevenção assim. (3)

As ações preventivas visam levar as pessoas a mudarem seus comportamentos, escolhendo estilos de vida mais saudáveis, e os ACS em suas ações levam as informações no sentido de despertar a intenção da mudança.

Um aspecto bastante interessante salientado por Nunes et. al. ${ }^{17}$, no que diz respeito às formas deabordagem, éque muitas vezes el as são desenvolvidas empiricamente pelos ACS em razão de várias formas de resistência, dentre elas, a nãoaceitação da proposição de mudança e a recusa pela visita dos membros da equipe.

Sob esta perspectiva de mudança de comportamentos, Abreu et al..$^{31}$ destacaram que os conceitos sobre saúde-doença sofrem forte influência dos val ores culturais, sendo necessária a compreen são deque tais conceitos e práticas são partes integrantes de redes de significados socioculturalmente construídas.

Por ser tratar de dimensões individual, cultural e social, e não somente um espaço físico, o trabalho em territórios busca o entendimento entreos diferentes sujeitos, almejando uma aproximação e diálogo, de modo a permitir um espaço para expressão dos traços cotidianos dos diferentes pares, além de possibilitar caminhos e ações conjuntas para a solução dos problemas.

Ainda, os entrevistados comentam sobre como vivenciam a oferta dos serviços de odontologia no seu cotidiano, e percebem restrições de acesso aos serviços, podendo tal lacuna ser observada pelas seguintes falas:

"mais acesso, no caso de médicos, da odontologia". (2)

"eles deveriam abrir mais vagas, abrir mais oportunidades, ou então, atémesmo colocar mais vagas para os pacientes". (3)

Ao vivenciar as ações em saúde bucal, os ACS percebem os serviços odontológicos em fase de crescimento para tornar-se acessível às pessoas, a saber:

"eu acredito que a saúde bucal aqui no Brasil está indo de vento em popa, eu tenho meus dentes perfeitos, épela oportunidadequeeu tive, pelo posto de saúde. Então, quem tem oportunidade tem que seguir, tem que fazer". (1)

"a gente sabe, surgiu o CEO" (3)

“hoje em dia tem até lugar que você pode buscar tratamento gratuito, mesmo que demore um pouquinho, você consegue". (8)

$\mathrm{Na}$ rotina diária, sentimentos de limitação permeiam o cotidiano dosACS, observados através dos seguintes discursos:

às vezes a gente não consegue atingir 0 objetivo que a gente gostaria. A gente não tem suporte. M uitasvezes, a gentequer fazer, mas não tem apoio necessário, não tem material. M as poderia ser meIhor, se a gente tivesse mais apoio, mais suporte. Falta material, falta um local para vocêfazer uma palestra, trabalhar direto com o povo para esclarecer mais. Dificuldade de um local para trabalhar com eles, salão para fazer palestra, papel para trabalhar. 0 computador não tem tinta. Investir mais, dando mais espaço para a gente trabalhar direto com a população. Palestra, ter um local para a gente estar falando com a população. (2)

porquea gente podeestar passando informação errada. Q ueaté mesmo o paci entechega na unidadeeacha queo trabalho do dentista éfazer "dentes novos", daí ele chega na unidade e não consegue 0 que eles querem. Daí fala que a higiene bucal ou então queo trabalho do PSF não valenada. Porque passam uma informação fantasiosa. Porque eles acham que vão chegar aqui e eles vão encontrar canal (tratamento), vão encontrar tudo de meIhor, como sefosse particular. No fundo, no fundo a 
gentesabequenão éassim, da forma queelesacham. A gente leva informação, eles vêm até o posto, daí não tem o material específico para estar fazendo o tratamento, e aí a gente passa por mentirosa. Então éisso quea gentequer. Passar informação certa para nós, para nós estarmos passando informação correta para os pacientes. (3)

M esmo reconhecendo o ACS como recurso importante na melhoria do acesso aos serviços odontológicos, sabe-se que, para a resolução dos problemas relacionados à demanda, faz-se necessário garantir a oferta de condições satisfatórias de trabalho, bem como de uma infra-estrutura mínima e adequada, com recursos humanos, materiais e financeiros disponíveis.

A última categoria se desvela com o ACS descrevendo a importância do conhecimento etambém sobre a renovação ou atualização dos conhecimentos em saúde bucal, como reportam as falas a seguir:

eu acho que a gente deveria ter mais conhecimento, eu acho quea gente deveria ter mais palestras. Conhecer mais o queé realmente cárie, o que não é, quais os tratamentos específicos que pode ser utilizado no PSF. 0 que a gente precisa mesmo é de palestra, quanto mais palestra, quanto mais ações que levarem para a área da higiene bucal, para nós vai ser muito mais gratificante. Porquea gente vai estar passando informação correta para os pacientes. (3)

principalmente na minha profissão, eu tenho que estar atenta a todas as informações que foram passadaspara mim, para queeu possa estar passando essasinformações aos pacientes eorientando também a importância da higiene. Reciclagem, lembrar, ir às oficinas, nos cursos, educação permanente, que eu acho muito importante, é essencial. (5)

a gente ter mais acesso às informações, através de cursos, de palestras, com pessoas, com dentistas da área, com doutorados da área. Para a gente é muito importante, para a gente poder passar para a comunidade uma orientação mais concreta. Quanto mais conhecimento a gentetiver, para mim émel hor, para a gentepoder ajudar a comunidade, na orientação. (7)

eu acho assim, que se pudesse dar mais treinamento nessa área, seria bom. Tudo é válido para a gente poder falar de uma maneira mais simples com as pessoas. (8)

por causa da gente ser agente comunitária, eu acho que a gente tem que saber, porque se a gente vai fazer as visitas, as pessoas não perguntam só da saúde, perguntam da saúdebucal também. Eu acho que o melhor modo de se aprimorar é com cursos, fazendo cursos, porque a gente aprende tanto nos cursos, então eu acho que o curso vale muito. (9)

Neste contexto, relativo ao processo formador equalificador do ACS, Solla 32 , em seu estudo sobre o trabalho do ACS na Bahia, concluiu que a maioria dos ACS se ressente de capacitações e de maior aprofundamento para melhor argumentarem junto às famílias.

Ainda a esse respeito, Oliveira33, quando analisou o trabalho dos ACS no M ato Grosso do Sul, concluiu queo ACS necessita de treinamento contínuo adequado evoltado para as realidades locais.

Com a finalidade de melhorar o conteúdo dos cursos de qualificação direcionados ao ACS, Torres e Lopes ${ }^{34}$ orientam que as experiências, oS temas da realidade local dos ACS e os temas inerentes à política nacional de saúde estejam contemplados no processo pedagógico, apontando para a necessidade de qualificação periódica.

Para que o ACS responda satisfatoriamente às expectativas que Ihes são apresentadas diante do exercício profissional, considera-se de fundamental importância o seu aprimoramento técnico-científico, de forma continuada, visando ao desenvolvimento de suas potencialidades eaquisição de novas competências e habilidades, as quais são exigidas pelo mercado e convívio globalizados.

Enfim, em todos os momentos dessa prazerosa viagem de conhecimento acerca do universo vivido pelos ACS, em que as palavras ditas e as não ditas falaram por si sobre o que somos e como abordamos o mundo, boas e oportunas descobertas se desvelaram, tornando-se muito significativas a partir de seus olhares, e se manifestaram em ensinamento e aprendizado.

Personagens e protagonistas de uma história que nos espaços de seus mundos de vida e trabaIho tornaram compreensíveis os significados que atribuem às suas realidades.

$E$, para fechar este segmento, este estudo foi apenas uma forma de desencadear processos de reflexão, ou talvez, esse foi apenas um modo de começar...

\section{Consideraçõesfinais}

N esse processo de idas e vindas de reflexão, percebe-se que, para que essa valiosa qualidade de elo não se rompa, deve-se ouvir e cuidar desses profissionais, e que sejam compreendidos, valorizados e respeitados, pois desenvolvem importantes papéis. 
Na tentativa de superar sentimentos elimitações, programas de desenvolvimento profissional com base na educação permanente em saúde devem ser proporcionados a esses trabal hadores, para que tenham novas concepções do seu trabalho diário, tornando sua trajetória profissional mais prazerosa. Assim como momentos de discussão, análise e reflexão possam ser proporcionados para que se percebam fazendo parte de uma equipe.

São como anjos que cuidam dos outros como se fossem membros de suas famílias e, com propriedade, se utilizam das tecnologias leves (a conversa, 0 acolhimento, a humanização, a escuta solidária, a mediação) e, dessa forma, ao darem uma nova forma ao ato de "cuidar" , acabam dando vida à produção do cuidado.

$\mathrm{Na}$ execução de suas rotinas, ora Ihes são exigidos conhecimentos com embasamento na me dicina "oficial", ora, saberes e experiências próprias, e assim entrecruzando-se os vários saberes vão tecendo em seu cotidiano um conjunto de conhecimentos. E nesse saber, o pensar e o fazer vão costurando dois universos culturais: 0 de saberes populares e o de saberes médico-científicos e, ao dominarem esses conhecimentos, vão se adentrando os lares, achegando-se às pessoas, repartindo conhecimentos, levando o saber simplificado, motivando as pessoas a refletirem so- bre comportamentos inadequados, influenciando inclusive na mudança de atitudes.

Para o usuário, a informação e a socialização do conhecimento sobre questões de educação e saúde são instrumentos vitais, para que, quando capacitado, ele possa gerir responsavelmente 0 próprio destino, deixando de ser simples objeto recebedor de serviços, sem vontade própria ou direito de escolhas. E para nós, profissionais em saúde bucal, são necessárias tais conquistas para que tenhamos um vislumbre de missão cumprida na busca de uma democracia social maisjusta.

Portanto, percebe-se o ACS como uma pessoa importante, ecomo mencionado por $\mathrm{Nunes}^{17}$, acredita-se na força e na riqueza desse trabalhador em saúde, contribuinte do processo de transformação social, mas que sozinho não podee não deve carregar a credibilidade do sistema de saúde.

Para pensar e agir é preciso ter certeza. E tal certeza está na luta diária, na qual se acredita ser possível que uma pequena mudança feita com qualidade e dirigida a um objetivo em comum seja capaz de operar grandes mudanças, tanto quantitativamente como qualitativamente.

$E$, nessa perspectiva, entendendo a boca em sua dimensão mais intensa como um "lugar de afirmação da Vida" ${ }^{18}$, segue-se passo a passo, e é desse modo que, por meio de falas, sorrisos e gritos, molda-se o presente e molda-se o futuro em direção à saúde para todos. 


\section{Colaboradores}

GA Kobayashi trabalhou na construção do referencial teórico-metodológico, aplicação dos instrumentos, análise dos dados e redação do artigo; RA Alvez-Souza trabalhou na construção do referencial teórico-metodológico, orientação na análise geral do estudo, elaboração das figuras, redação, aprimoramento e revisão final do artigo; ML Garanhani trabalhou na construção do referencial teórico-metodológico, orientação na elaboração dos instrumentos e orientação na análise dos resultados e $T$ M aeda trabalhou na redação do abstract.

\section{Agradecimentos}

Os autores agradecem aos ACS envolvidos no estudo, às coordenadoras das USF e à Autarquia Municipal da Prefeitura do Município de Londrina.

\section{Referências}

1. Organização Mundial da Saúde/Unicef. Fundo das Nações para a Infância. Cuidados Primários de Saúde. Relatório da Conferência Internacional sobre Cuidados Primários de Saúde. Alma Ata. URSS. Brasília: Unicef - Brasil; 1979.

2. Brasil. Ministério da Saúde. Secretaria Nacional de Programas Especiais de Saúde. Divisão Nacional de Saúde Bucal. Política Nacional de Saúde Bucal: Princípios, Objetivos, Prioridades. Brasília: M inistério da Saúde; 1991.

3. Brasil. M inistério da Saúde. Fundação Nacional de Saúde. Programa de Saúde da Família. Brasília: Ministério da Saúde; 1994.

4. Brasil. M inistério da Saúde. Equipes de Saúde Bucal. Série C, Projetos, Programas e Relatórios. Brasília: M inistério da Saúde; 2000.

5. Souza RAA. A saúde bucal nos Conselhos M unicipais de Saúde: da ação ao direito. [dissertação]. Araçatuba (SP): Universidade Estadual Paulista; 2000.

6. Alves-Souza RA, Saliba O. A Saúde Bucal em pauta: análise de registros dos Conselhos M unicipais de Saúde de municípios pertencentes à 17ạ Regional de Saúde do Estado do Paraná, Brasil. Cad Saúde Pública 2003; 19(5):1381-1388.

7. M anfredini MA. Abrindo a boca: reflexões sobre bocas, corações e mentes. In: Campos FCB; Henriques CM $P$, organizadores. Contra a maré à beira-mar: a experiência do SUS em Santos. São Paulo: Hucitec; 1997. p.70-87.

8. Manfredini MA. Um olho no peixe, o outro no gato: planejando a promoção da saúde na Atenção Primária. 2003 [acessado 2006 Jan 31]. Disponível em: http:// www.campinas.sp.gov.br/saude/ou/manfredini.doc

9. Souza DS, Caminha JAN, Ferreira MA, Tomita NE, Narvai PC, Gevaerd SP, Mendes WB. A inserção da Saúde Bucal no PSF. Rev. Bras. Odont. Saúde Coletiva 2001; 2(2):7-29.

10. Souza HM, Sampaio LFR. Atenção básica: políticas, diretrizes e modelos coetâneos no Brasil. In: Negri B, Faria R, Viana ALD, organizadores. Recursos Humanos em Saúde: política, desenvolvimento e mercado de trabalho. Campinas: Instituto de Economia/ UNICAM P; 2002. p.9-32.

11. Motta J I J, Buss P, Nunes TCM. Novos desafios para a formação de recursos humanos em saúde. Rev Olho Mágico 2001; 8(3):4-8.

12. Condón JAP. Sobre a construção histórica do conceito de Odontologia em Saúde Coletiva. Rev A ção Coletiva 1998; 1(1):7-26.

13. M inayo MC. Pesquisa social: teoria, método e criatividade. Petrópolis: Vozes; 1993.

14. Garanhani ML. Habitando o mundo da Educação em um currículo de enfermagem - um olhar à luz de $\mathrm{H}$ eidegger [dissertação]. Ribeirão Preto (SP): USP; 2004.

15. Martins J, Bicudo MA. A pesquisa qualitativa em psicologia: fundamentos e recursos básicos. São Paulo: Morais; 1989.

16. Wright M GM . 0 agente de saúde na atenção primária de saúde: da teoria à realidade. Rev Bras de Enf 1987; 40(4):183-189.

17. Nunes M O, Trad LB, Almeida BA, Homem CR, M elo M CIC. O agente Comunitário de Saúde: construção da identidade desse personagem híbrido e polifônico. Cad Saúde Pública 2002; 18(6):1629-1638. 
18. Souza ECF. Formação e trabalho em Odontologia: ampliar a clínica para construir uma nova cultura de cuidado em Saúde Bucal. 2004. In: III Conferência Estadual de Saúde Bucal do Rio Grande do Norte [acessado 2005 set 16]. Disponível em: http:// paginas.terra.com.br/saude/angel online/artigos/ art_sauco/saude_bucal_betinha.pdf

19. Brasil. M inistério da Saúde. Secretaria de Políticas de Saúde. Projeto Promoção da Saúde. As Cartas da Promoção da Saúde/M inistério da Saúde, Secretaria de Políticas de Saúde, Projeto Promoção da Saúde. Brasília: M inistério da Saúde; 2002.

20. Buss PM. Promoção da saúde e qualidade de vida. Cienc Saude Colet 2000; 5(1):163-177.

21. Jewkes R. Evaluating community development initiatives in $\mathrm{Health}$ Promotion. In: Thorogood $\mathrm{M}$, Coombes $Y$, editors. Evaluating health promotion Practice and methods. London: Oxford University Press; 2000. p. 129-139.

22. Laverack G, Wallerstein N. M easuring community empowerment: a fresh look at organizational domains. Health Promotion International 2001;16:179185. [acessado 2006 Fev 17]. Disponível em: http:// heapro.oxfordjournals.org/cgi/reprint/16/2/179

23. Kemenade S. Social capital as a health determinant How is it defined? Applied Research and Analysis Directorate. Policy Research Communications U nit. [serial on the Internet] 2002 . [cited 2006 Feb 17]. Available from: http://www.hc-sc.gc.ca/sr-sr/ alt formats/iacb-dgiac/pdf/pubs/hpr-rps/wp-dt/ 2003-0207-social-defin/2003-0207-social-defin_e.pdf

24. Sem A. D evelopment as freedom. 1999 [acessado 2006 Fev 17]. Disponível em: http://joaocs.no.sapo.pt/ Files/desenv\%20liberdade.pdf

25. Laverack G, Labonte R. A planning framework for community empowerment goals within health promotion. Health Policy Plan [serial on the Internet] 2000 [cited 2006 Feb 17]; ;15(3): [about 8 p.]. Available from: http://medstat.med.utah.edu/symposium/ docs/255.pdf
26. Vasconcelos E. 0 poder que brota da dor e da opressão: empowerment, sua história, teorias e estratégias. Rio de Janeiro: Paulus; 2004.

27. Wolf SMR. O significado psicológico da perda dos dentes em sujeitos adultos. Rev APCD 1998; 52(4):307-316.

28. Vargas $A M D$, Paixão HH. Perda dentária e seu significado na qualidade de vida de adultos usuários de serviço público de Saúde Bucal no Centro de Saúde Boa Vista, em Belo Horizonte. Cien Saude Colet 2005; 10(4):1015-1019.

29. M artins EM . Construindo o valor Saúde Bucal. Ação Coletiva 1999; 2(2):5-9.

30. Figueiredo GO, Brito DTS, Botazzo C. Ideologia, fetiche e utopia na Saúde: uma análise a partir da Saúde Bucal. Cien Saude Colet 2003; 8(3):753-763.

31. Abreu MHNG, Pordeus IA, Modena CM. Representações sociais de Saúde Bucal entre mães no meio rural de Itaúna (MG). Cien Saude Colet 2005; 10(1):245-259.

32. Solla JJP, M edina M G, Dantas M BP. O PACS na Bahia: avaliação do trabalho dos Agentes Comunitários de Saúde. Saúde em Debate 1994; 51:4-15.

33. Oliveira RG, Nachif MCA, Matheus M LF. $O$ trabaIho do Agente Comunitário de Saúde na percepção da comunidade de Anastácio, Estado do M ato Grosso do Sul. Acta Scientarium Health Sciences 2003; 25(1):95-101.

34. Torres ZF, Lopes BC. O ASC na equipe de Saúde da Família. Rev Olho Mágico 2003; 10(3):71-78.

Artigo apresentado em 22/02/2006

Aprovado em 02/03/2007

Versão final apresentada em 02/04/2007 